\title{
Review
}

Metabolic Risk/Epidemiology

Diabetes Metab J 2020;44:640-657

https://doi.org/10.4093/dmj.2020.0115

pISSN 2233-6079 · eISSN 2233-6087

DIABET\&S \& METABOLISM JOURNAL

\section{Nonalcoholic Fatty Liver Disease: A Drug Revolution Is Coming}

\author{
Soung Won Jeong \\ Division of Gastroenterology and Hepatology, Department of Internal Medicine, Soonchunhyang University Seoul Hospital, Soonchunhyang University \\ College of Medicine, Seoul, Korea
}

The worldwide prevalence of non-alcoholic fatty liver disease is around 25\%, and that of nonalcoholic steatohepatitis (NASH) ranges from $1.5 \%$ to $6.45 \%$. Patients with NASH, especially those with fibrosis, are at higher risk for adverse outcomes such as cirrhosis and liver-related mortality. Although vitamin E, pioglitazone, and liraglutide improved liver histology in randomized trials, there are currently no Food and Drug Administration-approved drugs for NASH. Five pharmacologic agents-obeticholic acid, elafibranor, cenicriviroc, resmetirom, and aramchol-are being evaluated in large, histology-based phase 3 trials. Within 2 to 4 years, new and effective drugs for the treatment of NASH are expected. Additionally, many phase 2 trials are ongoing for various agents. Based on the results of phase 2 and 3 trials, combination treatments are also being investigated. Future treatment strategies will comprise drug combinations and precision medicine based on the different phenotypes of NASH and treatment response of the individual patient.

Keywords: Drug therapy, combination; Fibrosis; Non-alcoholic fatty liver disease; Precision medicine; Therapeutics

\section{INTRODUCTION}

Nonalcoholic fatty liver disease (NAFLD) can be classified histologically into nonalcoholic fatty liver or nonalcoholic steatohepatitis (NASH). The worldwide prevalence of NAFLD is around $25 \%$, and that of NASH ranges from $1.5 \%$ to $6.45 \%$ [1]. Patients with NASH, especially those with fibrosis, are at higher risk for adverse outcomes such as cirrhosis and liver-related mortality [2-7]. The most important histological feature of NAFLD associated with long-term mortality is fibrosis (stage $2-4)[2,8,9]$. Therefore, one of the following two surrogates must be satisfied in phase $2 \mathrm{~b}$ or 3 trials for conditional approval of drug development: (1) resolution of NASH without worsening of fibrosis or (2) a reduction in fibrosis by one or more stages without worsening of NASH $[10,11]$. Although there are currently no Food and Drug Administration (FDA) approved drugs for NASH, vitamin E, pioglitazone, and liraglutide im- proved the liver histology of patients with NASH in randomized trials [12-16]. Despite its potential benefits, vitamin E has been associated with conflicting reports of increased overall mortality [17,18], in haemorrhagic stroke [19] and prostate cancer in males older than 50 [20]. Pioglitazone causes weight gain [12-14], and its usefulness for NASH is still under investigation. Therefore, these risks must be balanced with the potential benefit in NASH patients, who have no options for treatment other than lifestyle modification. At present, weight loss and lifestyle modification with diet and exercise is recommended as the first-line therapy [21-24]. However, long-term compliance with lifestyle modification is difficult to achieve and maintain in the target population. Therefore, a major unmet need for a new drug to resolve NASH and reverse liver fibrosis exists. Recent main therapeutic targets for NASH are bile acid pathway, insulin resistance, inflammation, thyroid hormone receptor (THR)- $\beta$ stimulation, hepatic lipid metabo-
Corresponding author: Soung Won Jeong (D) https://orcid.org/0000-0003-2855-6011 Division of Gastroenterology and Hepatology, Department of Internal Medicine, Soonchunhyang University Seoul Hospital, Soonchunhyang University College of Medicine, 59 Daesagwan-ro, Yongsan-gu, Seoul 04401, Korea

E-mail: jeongsw@schmc.ac.kr
This is an Open Access article distributed under the terms of the Creative Commons Attribution Non-Commercial License (https://creativecommons.org/licenses/by-nc/4.0/) which permits unrestricted non-commercial use, distribution, and reproduction in any medium, provided the original work is properly cited. 
lism, anti-fibrosis, and so on. Five pharmacologic agentsobeticholic acid (OCA; farnesoid X receptor [FXR] agonist), elafibranor (a peroxisome proliferator-activated receptor [PPAR] $\alpha$ and $\delta$ agonist), cenicriviroc (CVC; an dual antagonist of $\mathrm{C}-\mathrm{C}$ chemokine receptor [CCR] types 2 and 5), resmetriom (THR- $\beta$ agonist), and aramchol (stearoyl-CoA desaturase [SCD] 1 inhibitor)-improved liver histology in phase 2 studies [25-29], and are undergoing phase 3 studies to evaluate their long-term efficacy and safety. Additionally, multiple novel agents targeting NASH-related pathways are the subjects of phase 1 and 2 trials, and approximately 200 pharmacologic agents are being evaluated for NASH treatment. This review summarizes the mechanisms of action of the main pharmacologic agents and outlines the pivotal phase 2 and 3 studies that have been completed or are ongoing.

\section{DRUG CLASSIFICATION BASED ON THE ACTION OF MECHANISM}

\section{Bile acid pathways}

\section{Farnesoid $X$ receptor agonist, obeticholic acid}

OCA is derived from the primary human bile acid, chenodeoxycholic acid, which is a natural FXR agonist [30]. As a result of synthetic modification, OCA stimulates FXR activity 100fold more intensely than chenodeoxycholic acid [30]. FXR is a nuclear receptor that is highly expressed in the liver and small intestine, and plays an important role in the synthesis and enterohepatic circulation of bile acids (Fig. 1) [31]. FXR activation reduces bile acid synthesis by inhibiting the conversion of cholesterol to bile acids, and it possesses antiinflammatory and antifibrogenic activity [32]. Activation of FXR in the ileum also

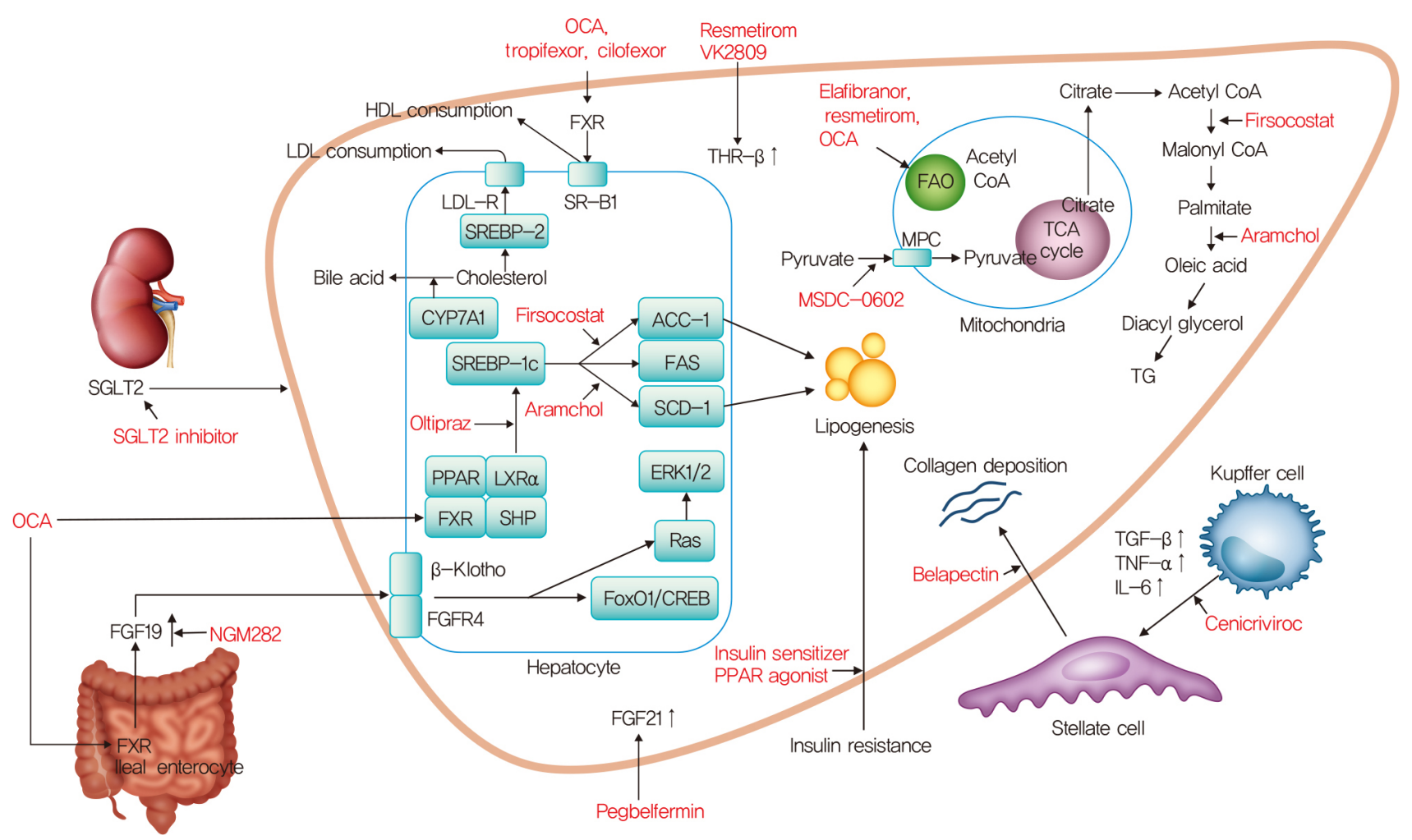

Fig. 1. Mechanism of action for nonalcoholic steatohepatitis treatment. OCA, obeticholic acid; HDL, high density lipoprotein; LDL, low density lipoprotein; SGLT2, sodium glucose cotransporter 2; FXR, farnesoid X receptor; THR- $\beta$, thyroid hormone receptor- $\beta$; LDL-R, low density lipoprotein receptor; SR-B1, scavenger receptor class B type 1; SREBP-2, sterol regulatory element-binding proteins-2; CYP7A1, cholesterol 7 $\alpha$-hydroxylase; SREBP-1c, sterol regulatory element binding protein-1c; ACC-1, acetyl-coenzyme A carboxylase-1; FAS, fatty acid synthase; SCD1, stearoyl-CoA desaturase 1; PPAR, peroxisome proliferator-activated receptor; LXR $\alpha$, liver X receptor $\alpha$; SHP, small heterodimer partner; ERK1/2, extracellular signal-regulated kinase 1/2; FGFR4, fibroblast growth factor receptor 4; FoxO1, forkhead box protein O1; CREB, cAMP response element-binding protein; FGF, fibroblast growth factor; FAO, fatty acid $\beta$-oxidation; CoA, coenzyme A; TCA, tricarboxylic acid; MPC, mitochondrial pyruvate carrier; TG, triglyceride; TGF- $\beta$, transforming growth factor- $\beta$; TNF- $\alpha$, tumor necrosis factor- $\alpha$; IL- 6 , interleukin- 6 . 
inhibits the uptake of bile acids by downregulating the sodium-dependent bile acid transporter. Finally, OCA exerts anticholestatic and hepatoprotective effects by regulating the metabolism of cholesterol and bile acids [33].

In a phase $2 \mathrm{a}$ clinical trial on OCA, patients with type 2 diabetes mellitus (T2DM) and NAFLD were randomly assigned to groups given placebo $(n=23), 25 \mathrm{mg} \mathrm{OCA}(n=20)$, or $50 \mathrm{mg}$ OCA $(n=21)$ once daily for 6 weeks (NCT00501592) [34]. Insulin sensitivity increased by $24.5 \%(P=0.011)$ in the combined OCA groups, whereas it decreased by $5.5 \%$ in the placebo group. The OCA groups had significant reductions in the levels of $\gamma$-glutamyltransferase $(\gamma$-GT) and alanine aminotransferase (ALT) and dose-related weight loss. Also, the levels of markers of liver fibrosis decreased significantly in the group treated with $25 \mathrm{mg}$ OCA. In a phase $2 \mathrm{~b}$ clinical trial, non-cirrhotic patients with NASH were randomly assigned 1:1 to groups given placebo $(n=142)$, and $25 \mathrm{mg}$ OCA $(n=141)$ once daily for 72 weeks (FLINT, NCT01265498) [25]. Fifty (45\%) of 110 patients in the OCA group had improved liver histology compared with 23 (21\%) of 109 patients in the placebo group (relative risk, 1.9; 95\% confidence interval [CI], 1.3 to 2.8; $P=0.0002$ ). Also, $23 \%$ of the OCA group developed pruritus compared with $6 \%$ of the placebo group. OCA improved the histological features of NASH, but its long-term benefit and safety need further clarification.

In the interim analysis of an ongoing, phase 3 study of OCA, patients with NASH, an NAFLD activity score (NAS) of at least 4, and fibrosis stages F2-F3, or F1 with at least one accompanying comorbidity were randomly assigned in a 1:1:1 ratio to receive oral placebo, OCA $10 \mathrm{mg}$, or OCA $25 \mathrm{mg}$ daily (GENERATE, NCT02548351) (Table 1) [35]. The primary analysis involved 931 patients with stage F2-F3 fibrosis (311 in the placebo group, 312 in the OCA $10 \mathrm{mg}$ group, and 308 in the OCA $25 \mathrm{mg}$ group). The fibrosis improvement endpoint was achieved by $37(12 \%)$ patients in the placebo group, $55(18 \%)$ in the OCA $10 \mathrm{mg}$ group $(P=0.045)$, and $71(23 \%)$ in the OCA 25 $\mathrm{mg}$ group $(P=0.0002)$. The NASH resolution endpoint was not met. However, the results of this interim analysis showed that OCA 25 mg significantly improved fibrosis and key components of NASH activity.

In the safety population (1,968 patients with fibrosis stages F1-F3) of this trial, the most common adverse event was pruritus, which occurred in 51\% of the OCA $25 \mathrm{mg}$ group, $28 \%$ of the OCA $10 \mathrm{mg}$ group, and $19 \%$ of the placebo group. Pruritis was generally mild to moderate in severity; however, $9 \%$ of the
OCA $25 \mathrm{mg}$ safety population discontinued the drug because of pruritus. The lipoprotein profile was also monitored in the safety population. The mean low density lipoprotein cholesterol (LDL-C) and total cholesterol levels peaked at 3 months in the OCA group. Also, 17\% of the OCA group and 7\% of the placebo group needed statin treatment.

A recent phase 2 trial (CONTROL, NCT02633956) evaluating the use of OCA combined with a statin for NASH showed that use of OCA at 5, 10, or $25 \mathrm{mg}$ daily increased the LDL-C level after 4 weeks of treatment, and the addition of atorvastatin $10 \mathrm{mg}$ decreased the LDL-C level to below baseline in all OCA groups by week 8 [36]. The combination of OCA and atorvastatin was generally safe and well tolerated.

The scope of OCA has been expanded to cirrhosis, and a phase 3 trial of OCA in patients with compensated cirrhosis due to NASH is ongoing. Patients were randomly assigned 1:1:1 to groups given $10 \mathrm{mg}$ OCA, $10 \mathrm{mg}$ with titration to $25 \mathrm{mg}$ OCA at 3 months, or placebo for 18 months (REVERSE, NCT03439254) (Table 1). The REVERSE study uses a dose-escalation approach as hepatic decompensation arises in patients with advanced cholestatic liver disease treated with OCA [37]. The primary endpoint is the proportion of subjects with improvement in fibrosis by at least one stage with no worsening of NASH.

\section{Non-bile acid FXR agonist}

\section{1) Tropifexor (LJN-452)}

Tropifexor (TXR; LJN452) is a highly potent, non-bile acid FXR agonist that induces the expression of target genes at very low doses without significant Takeda G-protein coupled receptor clone 5 activation [38]. A 48-week phase 2 trial on TXR in patients with NASH is ongoing (FLIGHT-FXR, NCT02855164) (Table 2) [39]. In an interim analysis after 12 weeks, similar to OCA, TXR demonstrated unfavorable lipid changes with a dose-related increase in the LDL-C level and a decrease in the high density lipoprotein cholesterol (HDL-C) level, in addition to pruritus, at higher doses compared with placebo. There was also a relative decrease in liver fat content by magnetic resonance imaging proton density fat fraction (MRI-PDFF) of $-9.8 \%$ in placebo, $-16.9 \%$ with TXR $60 \mathrm{mg}$, and $-15.6 \%$ with TXR $90 \mathrm{mg}$, in the interim analysis. Further analysis demonstrated that TXR was more efficacious in patients with a lower body mass index (BMI), suggesting that a weight-based dosing approach may be necessary [40]. 


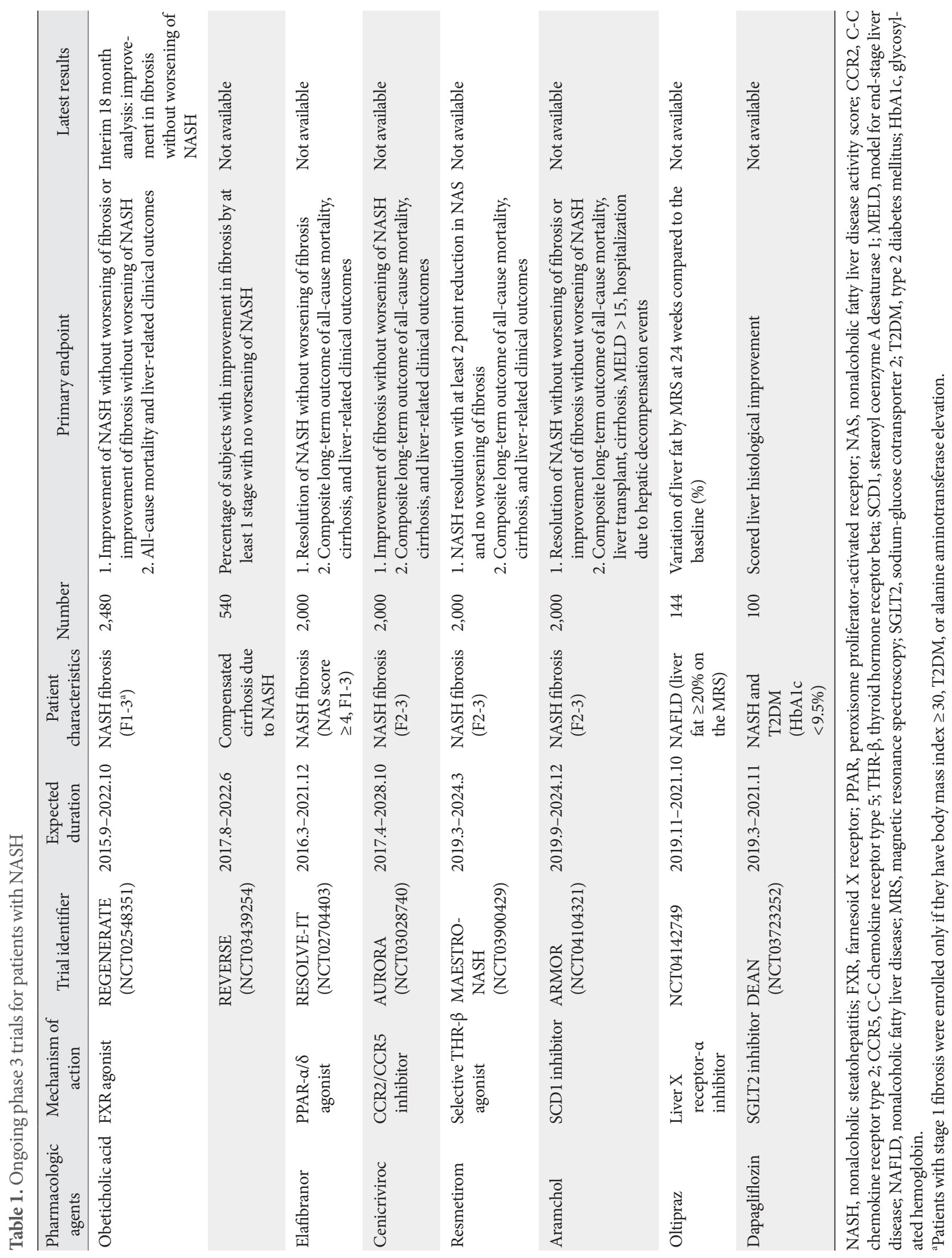




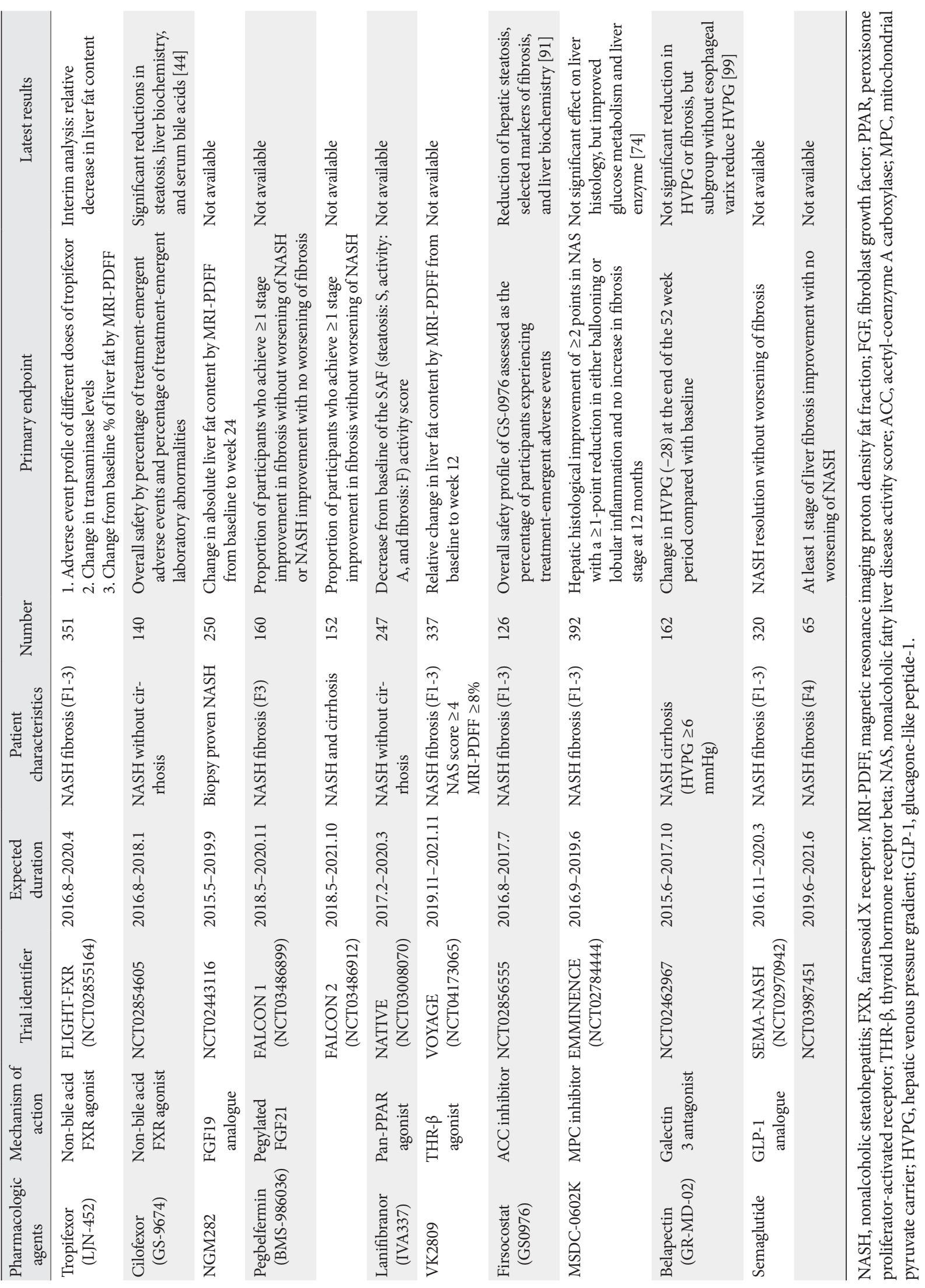




\section{2) Cilofexor (GS-9674)}

Because OCA has problematic side effects such as pruritus, hypercholesterolemia, and hepatic decompensation, selective non-bile acid synthetic FXR agonists have been developed. Cilofexor (GS-9674) is a potent, selective, nonsteroidal agonist of FXR that primarily functions to activate FXR in the intestine and does not undergo enterohepatic circulation [41]. Intestinal FXR agonism by cilofexor accentuates the physiologic release of fibroblast growth factor (FGF) 19, and may mitigate the detrimental effects of systemic FXR activation, including dyslipidemia, pruritus, and hepatotoxicity [41,42]. In a proof-of-concept study, 10 patients with NASH and F2-3 fibrosis who received $30 \mathrm{mg}$ of cilofexor once daily for 12 weeks experienced decreased hepatic fat level and stiffness, and improved liver biochemistry [43].

In a phase 2 trial, 140 non-cirrhotic and NASH patients were randomized to cilofexor $100 \mathrm{mg}(n=56)$, cilofexor $30 \mathrm{mg}$ $(n=56)$, or placebo $(n=28)$ for 24 weeks (NCT02854605) (Table 2) [44]. The results indicated that $100 \mathrm{mg}$ of cilofexor reduced the hepatic fat content and was reasonably well tolerated. Pruritus was not common but was more frequent in the $100 \mathrm{mg}$ (14\%) versus $30 \mathrm{mg}(4 \%)$ cilofexor and placebo groups (4\%). No difference in pruritus was seen at the $30 \mathrm{mg}$ dose compared with placebo but, like many other FXR agonists, cilofexor caused pruritis dose dependently, with more moderate to severe pruritus in those receiving $100 \mathrm{mg}$ daily compared with placebo. Cilofexor for 24 weeks resulted in significant reductions in hepatic steatosis, liver biochemistry, and serum bile acids in patients with NASH. Other FXR agonists (nidufexor [45], and EDP-305 [46]) have been developed and are in phase 2 trials.

\section{Fibroblast growth factor 19 analogue, NGM282}

The FGF family of hormones mediate metabolic functions and tissue repair and regeneration [47]. FGF19 is a downstream target of FXR activation, with FXR initiating FGF19 secretion by the intestine. FGF19 is a hormone that regulates bile acid synthesis and glucose homeostasis [48], and NGM282 is an engineered analogue of FGF19 (Fig. 1).

In a phase 2 study, 82 patients with biopsy proven NASH were randomly assigned to receive $3 \mathrm{mg}(n=27)$ or $6 \mathrm{mg}$ subcutaneous NGM282 $(n=28)$ or placebo $(n=27)$ (NCT02443116) [49]. The primary endpoint was the absolute change in liver fat content from baseline to week 12. Responders were patients who achieved a $5 \%$ or greater reduction in absolute liver fat content as measured by MRI-PDFF. At 12 weeks, 20 (74\%) patients in the $3 \mathrm{mg}$ dose group and $22(79 \%)$ in the $6 \mathrm{mg}$ dose group achieved at least a $5 \%$ reduction in absolute liver fat content from baseline versus two (7\%) in the placebo group. NGM282 produced rapid and significant reductions in liver fat content with an acceptable safety profile in patients with NASH. In a recent open-label study, the histological efficacy of NGM282 in patients with biopsy proven NASH was assessed [50].

Paired liver biopsies from 43 patients who received subcutaneous NGM282 (1 mg, $n=24 ; 3 \mathrm{mg}, n=19)$ once daily for 12 weeks were evaluated, blinded to time point, subject, and clinical information. At week 12, NGM282 improved the histological features of NASH, with significant reductions in the NAS and fibrosis scores, accompanied by improvements in noninvasive imaging and serum markers. A larger phase 2 study with a target of 250 participants with biopsy proven NASH is currently actively recruiting (NCT02443116) (Table 2).

\section{Pegylated fibroblast growth factor 21, pegbelfermin (BMS-986036)}

FGF21 has also been implicated in bile acid pathways. Activation of FXR, together with PPAR $\alpha$, induces hepatic expression and secretion of FGF21 [51]. FGF21, a non-mitogenic hormone, is a key regulator of energy metabolism [52]. Endogenous FGF21 has a short half-life of 1 to 2 hours, but various modification strategies have been used to create longer-acting FGF21 analogues [53]. Pegbelfermin (BMS-986036) is a polyethylene glycol-conjugated recombinant analogue of human FGF21 with a prolonged half-life that enables up to weekly dosing.

In a randomized, double-blind, phase 2a study, 75 patients with a BMI of at least $25 \mathrm{~kg} / \mathrm{m}^{2}$, biopsy-confirmed NASH (fibrosis stage 1-3), and a hepatic fat fraction of at least $10 \%$ by MRI-PDFF were randomized into three groups (25 patients to receive $10 \mathrm{mg}$ pegbelfermin once daily; 24 to receive $20 \mathrm{mg}$ pegbelfermin once weekly, and 26 to receive placebo) [54]. There was a significant decrease in the absolute hepatic fat fraction in the group receiving $10 \mathrm{mg}$ pegbelfermin daily and in the group receiving $20 \mathrm{mg}$ pegbelfermin weekly compared with the placebo group. Most adverse events were mild; the most common was diarrhea in eight (16\%) of 49 patients treated with pegbelfermin. Treatment with pegbelfermin for 16 weeks was generally well tolerated and significantly reduced the hepatic fat fraction in patients with NASH. Currently, two large phase 2 trials (FALCON 1, $n=160$; FALCON 2, $n=152$ ) 
are ongoing to assess the safety and efficacy of pegbelfermin (NCT03486899 and NCT03486912, respectively) (Table 2).

\section{Insulin resistance}

\section{Peroxisome proliferator-activated receptor agonist}

1) Elafibranor

PPARs are nuclear receptors playing key roles in cellular processes regulating metabolic homeostasis, immune-inflammation, and differentiation. There are three nuclear receptor isoforms, PPAR $\alpha, \operatorname{PPAR} \beta / \delta$, and PPAR $\gamma$, which are encoded by different genes [55]. Elafibranor (GFT505) is a dual a PPAR $\alpha$ and $\delta$ agonist, and it regulates lipid and insulin metabolism. PPAR $\alpha$ is most prominently expressed in the liver and is activated by hypolipidemic fibrates. PPAR $\alpha$ controls the lipid flux in the liver by modulating fatty acid transport and $\beta$-oxidation and improves plasma lipids by decreasing the triglyceride level and increasing that of HDL-C [56]. In advanced NASH, the PPAR $\alpha$ level is reduced but recovers after improvement [57]. $\operatorname{PPAR} \delta$ (also called PPAR $\beta$ ) regulates metabolism in the liver and peripheral tissues. PPAR $\delta$ agonists enhance fatty acid transport and oxidation, increase the HDL level, and improve glucose homeostasis by enhancing insulin sensitivity and inhibiting hepatic glucose output [58]. In a pilot trial, a selective PPAR $\delta$ agonist reduced liver fat content, improved insulin sensitivity and plasma lipid levels, and decreased the $\gamma$-GT level [59].

In a phase $2 \mathrm{~b}$ clinical trial on elafibranor, patients with NASH without cirrhosis were randomized to receive elafibranor $80 \mathrm{mg}(n=93)$, elafibranor $120 \mathrm{mg}(n=91)$, or placebo $(n=$ 92) daily for 52 weeks (GOLDEN-505, NCT01694849) [26]. The primary outcome was resolution of NASH without fibrosis worsening, using protocol-defined and modified definitions. In an intention-to-treat analysis, there was no significant difference between the elafibranor and placebo groups in the primary outcome. However, in a post hoc analysis of patients with NAS $\geq 4(n=234)$, elafibranor $120 \mathrm{mg}$ resolved NASH in a larger proportion of patients than placebo based on the protocol definition ( $20 \%$ vs. $11 \%$; odds ratio, $3.16 ; P=0.018)$ and the modified definitions ( $19 \%$ vs. $9 \%$; odds ratio, 3.52; $P=0.013$ ). Also, patients in whom NASH resolved after receiving elafibranor $120 \mathrm{mg}$ had reduced liver fibrosis compared to those without NASH resolution. The levels of liver enzymes, lipids, and markers of systemic inflammation, as well as the glucose profile, were significantly reduced in the elafibranor $120 \mathrm{mg}$ group versus the placebo group. Elafibranor was well tolerated and did not cause weight gain or cardiac events, but did produce a mild, reversible increase in the serum creatinine level.

A phase 3 trial on elafibranor in 2,000 NASH patients (NAS $\geq 4$ ) with stage $2 / 3$ fibrosis is ongoing (RESOLVE-IT, NCT02704403) (Table 1). The primary outcome is the proportion of patients with resolution of NASH without worsening of fibrosis at 72 weeks. The trial also evaluated a composite long-term outcome composed of all-cause mortality, cirrhosis, and liverrelated clinical outcomes at 4 years. The trial began in March 2016, and the results are due in December 2021.

\section{2) Lanifibranor}

Lanifibranor (IVA337) is a moderately potent agonist of all three PPAR isoforms, with well-balanced activation of PPAR $\alpha$ and PPAR $\delta$ and partial activation of PPAR $\gamma$ [60]. While other PPAR agonists target one or two PPAR isoforms, lanifibranor is the only pan-PPAR agonist in clinical development.

In a phase $2 \mathrm{~b}$ clinical trial on lanifibranor (IVA337) in NASH patients with liver steatosis and moderate to severe necroinflammation without cirrhosis, 247 patients were randomly assigned to receive lanifibranor $800 \mathrm{mg}, 1200 \mathrm{mg}$, or placebo per day for 24 weeks (NATIVE, NCT03008070) (Table 2). The primary endpoint was a decrease from baseline in the SAF (steatosis, S; activity, A; and fibrosis, F) activity score. The study began in January 2017 and was completed in March 2020. Initial results are expected in the first half of 2020.

\section{Glucagon-like peptide-1 receptor agonist, semaglutide}

No pharmacotherapies have been established for patients with NASH and T2DM. The main point is to determine the best antidiabetic drugs for treatment of NASH, to prevent the progression of hepatic fibrosis and cardiovascular or renal events. Glucagon-like peptide-1 receptor agonists (GLP-1 RAs) and sodium-glucose cotransporter 2 (SGLT2) inhibitors are expected to ameliorate NASH and NAFLD. GLP-1 is a gut-derived incretin hormone that induces weight loss and insulin sensitivity. GLP-1 analogs are approved for use in patients with T2DM and obesity. These analogs provide the benefits of weight loss, improved glycemic control, fewer hypoglycemic events, and a reduced frequency of major cardiovascular events $[61,62]$. There is interest in the therapeutic role of GLP-1 RAs for NAFLD and NASH [15,63-66].

In a recent randomized, placebo-controlled trial involving 52 patients with biopsy-proven NASH, $1.8 \mathrm{mg}$ of liraglutide administered subcutaneously daily for 48 weeks was associated with greater resolution of NASH and less progression of fibro- 
sis [15]. However, the American Association for the Study of Liver Diseases practice guidance 2018 recommended that it is premature to consider GLP-1 agonists for treating liver disease in patients with NAFLD or NASH [24].

Semaglutide is a novel GLP-1 analogue with an extended half-life of approximately 1 week. In a phase 2 study of the effect of semaglutide on NASH, 320 patients with NASH were randomly assigned to placebo or three dose levels of semaglutide subcutaneously for 72 weeks (NCT02970942) (Table 2). The primary endpoint was NASH resolution without worsening of fibrosis. Initial results from the study are expected in May 2020, with completion anticipated in July 2020. Another phase 2 study of semaglutide involves once-weekly injection of semaglutide, $2.4 \mathrm{mg}$, for 48 weeks. The primary outcome is improvement of liver fibrosis by at least 1 stage with no worsening of NASH after 48 weeks (NCT03987451) (Table 2). Semaglutide is the most promising of various GLP-1 analogues for the treatment of diabetic NASH. However, whether GLP-1 analogues improve hepatic inflammation or fibrosis in NASH is unknown.

\section{Sodium-glucose cotransporter 2 inhibitor, dapagliflozin}

SGLT2 inhibits glucose reabsorption in the proximal tubule, leading to glucouria and a reduction in the plasma glucose level. Therefore, SGLT2 inhibitors have therapeutic potential for NASH and NAFLD. Small studies have shown the effect of dapagliflozin in patients with NAFLD and T2DM $[67,68]$. Although the possibility cannot be excluded that the reduction in body weight or visceral adipose tissue caused by dapagliflozin may be associated with a decrease in liver steatosis or fibrosis, dapagliflozin showed a beneficial effect in patients with NAFLD. A multicenter, randomized, placebo-controlled, phase 3 clinical trial is ongoing to assess the efficacy and safety of dapagliflozin for treating NASH (DEAN, NCT03723252) (Table 1). The primary endpoint is improvement of the liver histological score at 12 months. One-hundred patients with NASH were randomly assigned to placebo or $10 \mathrm{mg}$ of dapagliflozin. The study began in March 2019, and the results are due in November 2021.

\section{Mitochondrial target of thiazolidinedione, MSDC-0602K}

First-generation insulin-sensitizing thiazolidinediones directly bind to and activate the PPAR $\gamma$ nuclear hormone receptor and are used to treat T2DM [69]. However, they are associated with significant side effects including edema, bone fractures mediated by PPAR $\gamma$, and hypoglycemia. The second-generation in- sulin sensitizer MSDC-0602K was designed to reduce these side effects, while still producing insulin sensitizing pharmacology in animal models of diabetes [70] and NASH [71]. It modulates the effects of over-nutrition at the level of the mitochondrial pyruvate carrier (MPC) with minimal PPAR $\gamma$ binding (Fig. 1) [72]. Initial studies showed that MSDC-0602 could increase lipid oxidation and reduce de novo lipid synthesis and gluconeogenesis in the liver, both in vivo and in vitro, without the side-effects of first-generation insulin sensitizers [73].

In a 52-week randomized, double-blind, placebo-controlled phase $2 \mathrm{~b}$ study, patients with biopsy-confirmed NASH and fibrosis (F1-F3) were randomly assigned to placebo $(n=94)$, or $62.5 \mathrm{mg}(n=99), 125 \mathrm{mg}(n=98)$, or $250 \mathrm{mg}(n=101)$ of MSDC-0602K (EMMINENCE, NCT02784444) (Table 2) [74]. The primary efficacy endpoint was hepatic histological improvement of $\geq 2$ points in NAS with a $\geq 1$-point reduction in ballooning or lobular inflammation and no increase in fibrosis stage at 12 months. In that study, MSDC-0602K did not exert a significant effect on liver histology. However, MSDC-0602K significantly decreased the levels of fasting glucose, insulin, glycated hemoglobin, and markers of liver injury without dose-limiting side effects. A phase 3 study will be initiated in 2020 (MMONARCh, NCT03970031).

\section{Inflammation}

C-C chemokine receptor types 2 and 5 antagonist, cenicriviroc $\mathrm{CVC}$ is an oral, dual antagonist of CCR2 and CCR5. Blockade of CCR2, a chemokine receptor predominantly expressed on monocytes and macrophages, results in reduced recruitment, migration and infiltration of these cells to the injured parts of the liver [75,76]. Parallel CCR5 inhibition impairs the migration, activation and proliferation of activated hepatic stellate cells $[76,77]$.

In a phase $2 \mathrm{~b}$ trial on $\mathrm{CVC}$ in patients with NASH (NAS $\geq 4$ ) with fibrosis (stages $1-3)$, patients $(n=289)$ were randomly assigned CVC $150 \mathrm{mg}$ or placebo. The primary outcome was a $\geq 2$-point improvement in NAS and no worsening of fibrosis at 1 year (CENTAUR, NCT02217475) [27,78]. The primary endpoint of NAS improvement in the intention-to-treat population and resolution of NASH was achieved in a similar proportion of subjects on CVC $(n=145)$ and placebo. However, the fibrosis endpoint was met in significantly more subjects on CVC than placebo ( $20 \%$ vs. $10 \%, P=0.02)$. Treatment benefits were greater in those with higher disease activity and fibrosis stage at baseline. After 1 year of CVC treatment, twice as many sub- 
jects achieved improvement in fibrosis and no worsening of NASH compared with placebo.

AURORA (NCT03028740), a randomized, double-blind, placebo-controlled, multicenter phase 3 study is ongoing to evaluate the efficacy and safety of CVC for the treatment of liver fibrosis in 2,000 NASH patients with stage 2/3 fibrosis (Table 1). The study will be conducted in two parts. Part 1 will examine the surrogate endpoint of improvement in fibrosis of at least one stage and no worsening of NASH at 12 months. Subjects from part 1 will continue into part 2 and additional subjects will be newly randomized in part 2 to determine longterm clinical outcomes-histopathologic progression to cirrhosis, liver-related clinical parameters, and all-cause mortality. The trial began in April 2017, and the results are expected in December 2024.

\section{Thyroid hormone receptor- $\beta$ agonist \\ 1) Resmetirom (MGL-3196)}

The THR- $\beta$ is highly expressed in hepatocytes. NASH might be, in part, a condition of diminished liver thyroid hormone levels or hepatic hypothyroidism, and the incidence of clinical and subclinical hypothyroidism is higher in patients with NAFLD or NASH relative to age-matched controls $[79,80]$. THR- $\beta$ stimulation is responsible for the beneficial metabolic effects on triglycerides and cholesterol levels as well as improvements in hepatic steatosis [79]. With a favorable cardiometabolic profile and the alleviation of hepatic steatosis, THR- $\beta$ agonists are being investigated for the treatment of NASH.

Resmetirom (MGL-3196) is a liver-directed, orally active, selective THR- $\beta$ agonist designed to improve NASH by increasing hepatic fat metabolism and reducing lipotoxicity. In a phase 2 study, patients with biopsy-confirmed NASH (fibrosis stages $1-3$ ) and a hepatic fat fraction $\geq 10 \%$ by MRI-PDFF, were randomly assigned 2:1 to receive resmetirom $80 \mathrm{mg}$ or matching placebo, orally once daily (NCT02912260) [28].

The primary outcome was the percentage of change from baseline in hepatic fat fraction assessed by MRI-PDFF at 12 weeks. Resmetirom treatment resulted in a significant reduction in the hepatic fat fraction after 12 and 36 weeks. Resmetirom was well tolerated but caused an increase in gastrointestinal adverse events, which were self-limited and did not result in study withdrawal.

A phase 3 trial involving 2,000 NASH patients with stage 2/3 fibrosis is ongoing (MAESTRO-NASH, NCT03900429) (Table 1). The primary outcome is the effect of resmetirom 80 or 100 mg compared to placebo on liver histology, and there is a composite long-term outcome of the number of patients with onset of any of the adjudicated events-cirrhosis, all-cause mortality, and liver-related clinical parameters. The trial began in March 2019, and the results are due in March 2024.

\section{2) VK2809}

VK2809 is a small-molecule prodrug of a potent THR- $\beta$ agonist. VK2809 is selectively cleaved in hepatic tissue by cytochrome P450 isozyme 3A4, to release a pharmacologically active metabolite. In a phase $2 \mathrm{a}$ trial, patients with a liver fat content of $\geq 8 \%$ as assessed by MRI-PDFF, an LDL-C level of $\geq 110$ $\mathrm{mg} / \mathrm{dL}$, and a triglyceride level of $\geq 120 \mathrm{mg} / \mathrm{dL}$ were randomized to receive oral VK2809 at $5 \mathrm{mg}$ once daily, $10 \mathrm{mg}$ once every other day, $10 \mathrm{mg}$ once daily, or placebo for 12 weeks [81].

Patients receiving VK2809 experienced a significant reduction in liver fat content by MRI-PDFF, relative to placebo. The median relative change from baseline in liver fat content was $53.8 \%$ for VK2809 $5 \mathrm{mg}$ once daily $(P=0.0001), 56.5 \%$ for VK2809 $10 \mathrm{mg}$ once every other day $(P=0.0018)$, and $59.7 \%$ for VK2809 10 mg once daily $(P=0.0004)$, versus $9.4 \%$ for placebo.

Based on these results, a phase $2 \mathrm{~b}$ study is ongoing in 337 patients with biopsy proven NASH, to assess the efficacy and safety of VK2809 (1.0, 2.5, 5.0, $10 \mathrm{mg}$ ) versus placebo for 52 weeks. The primary outcome is the relative change in liver fat content (assessed by MRI-PDFF) from baseline to 12 weeks (VOYAGE, NCT04173065). The study began in November 2019.

\section{Hepatic lipid metabolism}

\section{Stearoyl-CoA desaturase 1 inhibitor, aramchol}

Arachidyl amido cholanoic acid (aramchol) is a novel synthetic lipid molecule that is a conjugate of cholic acid (a bile acid) and arachidic acid (a fatty acid). It inhibits SCD1, which converts saturated fatty acids into monounsaturated fatty acids (Fig. 1) [82]. Aramchol has been studied in a phase 2 a trial over 3 months at doses of 100 and $300 \mathrm{mg}$ daily. This study demonstrated a reduction in liver fat by magnetic resonance spectroscopy (MRS) after 3 months of treatment in the group receiving aramchol, $300 \mathrm{mg}$, compared with placebo, but not in the group receiving $100 \mathrm{mg}$. There was also a reduction in the ALT level and the compound was well tolerated [83]. Higher doses of aramchol (400 and $600 \mathrm{mg}$ ) were administrated to patients with biopsy proven NASH $(n=247)$ without cirrhosis in a phase $2 b$ trial that evaluated their effect on the hepatic triglyc- 
eride content using MRS and liver biopsy (ARREST, NCT02279524 ) [29]. There was a significant $\geq 5 \%$ reduction in liver fat content with $600 \mathrm{mg}$ aramchol, 47\%, compared with placebo, $24 \%$. According to liver histology, NASH resolution without worsening of fibrosis occurred more often with aramchol, $600 \mathrm{mg}$, than placebo ( $16.7 \%$ vs. $5 \%$; odds ratio, $4.74 ; 95 \% \mathrm{CI}$, 0.99 to 22.66). Although the study was underpowered for histological assessment, a dose-response trend toward NASH resolution and fibrosis improvement was seen. A phase 3/4, multinational, multicenter, double-blind, placebo-controlled study to evaluate the efficacy and safety of aramchol in subjects with NASH (fibrosis 2 or 3) who are overweight or obese and have prediabetes or T2DM (ARMOR, NCT04104321) has been proceeding since September 2019 (Table 1).

\section{Liver $X$ receptor- $\alpha$ inhibitor, oltipraz}

Oltipraz, is a synthetic dithiolethione that functions as an antisteatotic agent by inhibiting liver X receptor $\alpha(\mathrm{LXR} \alpha)$ activity (Fig. 1) [84]. Dithiolethiones, a novel class of adenosine monophosphate-activated protein kinase (AMPK) activators, prevent insulin resistance by inhibiting AMPK-dependent p70 ribosomal S6 kinase-1 (S6K1). AMPK is a serine/threonine kinase that plays a crucial role in the regulation of carbohydrate and fat metabolism, and it may modulate LXR $\alpha$ activity and decrease the expression of sterol regulatory element binding protein 1c (SREBP-1c), a key regulator of lipid production [85]. Oltipraz possesses therapeutic potential for steatosis by activating AMPK and inactivating S6K1. It also expedites lipid oxidation by inhibiting LXR $\alpha$ activity and decreasing the expression of SREBP-1c in the liver [84]. In a current phase 2 study, patients with a liver fat content of $>20 \%$ and hypertransaminasemia were randomized to three groups: placebo $(n=22), 30 \mathrm{mg}$ of oltipraz $(n=22)$, or $60 \mathrm{mg}$ of oltipraz $(n=24)$ twice daily for 24 weeks (PMK-N01GI1, NCT01373554) [86]. The primary outcome was the change in the liver fat content assessed by MRS from baseline to 24 weeks.

Compared with the placebo group, oltipraz significantly reduced the liver fat content in a dose-dependent manner. However, the absolute changes in insulin resistance and the levels of liver enzymes, lipids, and cytokines were not significantly different among the groups. Also, the incidence of adverse events was comparable among the groups.

A multicenter, randomized, double-blind, placebo-controlled, parallel, phase 3 clinical trial is ongoing to evaluate the efficacy and safety of oltipraz in 144 patients with NAFLD
(NCT04142749) (Table 1). The primary outcome is the variation in liver fat content by MRS at 24 weeks compared to baseline. The trial began in December 2019, and initial results are expected in October 2021.

\section{Acetyl-coenzyme A carboxylase inhibitor, firsocostat (GS0976)}

The regulation of de novo lipogenesis (DNL) plays a central role in fatty acid synthesis and catabolism. The rate-limiting step in DNL is conversion of acetyl-coenzyme A (acetyl-CoA) to malonyl-CoA by the enzyme acetyl-CoA carboxylase (ACC). ACC has two isoforms. The ACC1 isoform catalyzes the formation of malonyl-CoA, the main substrate for fatty acid biosynthesis in the cytosol. ACC2 is localized in mitochondria, where malonyl-CoA serves as a potent allosteric inhibitor of carnitine palmitoyl-transferase (CPT) 1 , the carrier protein of fatty acids into mitochondria for $\beta$-oxidation $[83,87]$. Inhibition of ACC1 and ACC2 would be expected to reduce DNL and enhance mitochondrial $\beta$-oxidation, respectively, supporting ACC inhibition as a therapeutic target in NASH [88-90]. Firsocostat (GS-0976) is a liver-targeted, smallmolecule allosteric inhibitor of both ACC1 and ACC2 in development for the treatment of NASH (Fig. 1).

In a recent phase 2 trial, 126 patients with hepatic steatosis of $\geq 8 \%$ based on MRI-PDFF and liver stiffness of $\geq 2.5 \mathrm{kPa}$, based on MRE, or historical biopsy consistent with NASH and F1-F3 fibrosis, were randomly assigned (2:2:1) to receive GS-0976 (20 $\mathrm{mg}$ ), GS-0976 (5 mg), or placebo daily for 12 weeks. In that study, administration of $20 \mathrm{mg}$ of GS-0976 was safe and led to a significant reduction in hepatic fat content by MRI-PDFF and a decreased serum level of tissue inhibitor of metalloproteinase 1 (TIMP1), a marker of fibrogenesis (NCT02856555) (Table 2) [91].

\section{Anti-fibrotic agents}

\section{Galectin-3 antagonist, belapectin (GR-MD-02)}

Galectins are carbohydrate-binding proteins belonging to the family of non-integrin $\beta$ galactoside-binding lectins [92]. Galectin-3 (Gal-3) is the most prominent galectin secreted in disease, mainly by macrophages. Gal-3 via its intracellular (antiapoptotic, macrophage differentiation) and extracellular (chemokinetic/chemotactic factor) effects is relevant to the physiopathology of hepatic fibrosis caused by various chronic liver diseases [93-96]. Galectin inhibitors are a new class of agents that target both secreted and membrane-associated galectins 
by virtue of their high molecular weight [97]. Belapectin (GRMD-02, galactoarabino-rhamnogalacturonate) is a complex carbohydrate molecule derived from a natural plant compound, which has oligosaccharide chains containing galactose residues and binds to galectin-3 and, to a lesser extent, galectin-1. A phase 1 study has shown that belapectin is safe and well tolerated at single and multiple doses of 2,4 , and $8 \mathrm{mg} / \mathrm{kg}$ in patients with well-characterized NASH and advanced fibrosis but not cirrhosis [98].

In a multicenter, randomized, double-blind, placebo-controlled phase $2 \mathrm{~b}$ trial, 162 patients with NASH, cirrhosis, and portal hypertension (hepatic venous pressure gradient [HVPG] $\geq 6 \mathrm{~mm} \mathrm{Hg}$ ) were randomly assigned to receive biweekly infusions of belapectin $2 \mathrm{mg} / \mathrm{kg}(n=54), 8 \mathrm{mg} / \mathrm{kg}(n=54)$, or placebo $(n=54)$ for 52 weeks (Table 2) [99]. The primary endpoint was the change in HVPG $(-28)$ at the end of the 52 week period compared with baseline. Belapectin was safe but was not associated with a significant reduction in HVPG or fibrosis, compared with placebo. However, in a subgroup analysis of patients without esophageal varices, $2 \mathrm{mg} / \mathrm{kg}$ belapectin did reduce HVPG and the development of varices. A phase 3 study to evaluate the safety and efficacy of belapectin for the prevention of esophageal varices in patients with NASH cirrhosis without esophageal varices is being initiated (NCT 04365868).

\section{COMBINATION THERAPY}

NASH is a multifactorial disease involving different contributing mechanisms, with no approved therapies. As a future therapeutic direction, drug combinations are promising because of targeting multipul NASH pathways. Most drug combinations comprise metabolic, inflammatory, and fibrotic agents; alternatively, an antidiabetic may be included. Recently, there are various combination therapeutic options for NASH (Table 3).

\section{TXR and CVC}

A recent randomized, double-blind, multicenter, phase $2 \mathrm{~b}$ study is ongoing to evaluate the safety and efficacy of the combination of TXR and CVC in 200 patients with NASH fibrosis (stages 2/3) (TANDEM, NCT03517540) (Table 3) [100]. Patients are randomized in a 1:1:1:1 ratio to receive TXR $140 \mu \mathrm{g}$ once daily, CVC $150 \mathrm{mg}$ once daily, TXR $140 \mu \mathrm{g}+\mathrm{CVC} 150 \mathrm{mg}$ once daily, or TXR $90 \mu \mathrm{g}+\mathrm{CVC} 150 \mathrm{mg}$ once daily. The study comprises a 48-week treatment period and a 4-week follow-up. The primary objective is evaluation of the safety and tolerability of the combination therapy compared with the monotherapies over 48 weeks. The secondary objective is efficacy, as defined by a $\geq 1$-point improvement in liver fibrosis versus baseline or resolution of steatohepatitis after 48 weeks. This combination treatment targets the steatotic, inflammatory, and/or fibrotic pathways implicated in NASH.

\section{Selonsertib, firsocostat, and cilofexor}

A recent phase 2 study evaluated the safety and efficacy of a selonsertib, firsocostat, and cilofexor combination in patients with bridging fibrosis or compensated cirrhosis caused by NASH (ATLAS, NCT03449446) (Table 3). The primary objectives were to assess the safety and tolerability of selonsertib, firsocostat, and cilofexor, administered alone or in combination, and the changes in liver fibrosis without worsening of NASH. The data will be presented in 2020 .

Table 3. Selective combination treatments for NASH

\begin{tabular}{lcccccc}
\hline Combination agents & Phase & Trial identifier & $\begin{array}{c}\text { Expected } \\
\text { duration }\end{array}$ & $\begin{array}{c}\text { Patient } \\
\text { characteristics }\end{array}$ & Number & Primary endpoint \\
\hline $\begin{array}{l}\text { Tropifexor, } \\
\text { cenicriviroc }\end{array}$ & 2 & $\begin{array}{c}\text { TANDEM, } \\
\text { NCT03517540 }\end{array}$ & $2018.9-2020.9$ & NASH fibrosis (F2-3) & 200 & $\begin{array}{c}\text { Safety and tolerability of combination } \\
\text { therapy }\end{array}$ \\
$\begin{array}{l}\text { Selonsertib, } \\
\text { firsocostat, cilofexor }\end{array}$ & 2 & $\begin{array}{c}\text { ATLAS, } \\
\text { NCT03449446 }\end{array}$ & $2018.3-2019.11$ & $\begin{array}{c}\text { Bridging fibrosis or } \\
\text { compensated cirrhosis } \\
\text { due to NASH }\end{array}$ & $\begin{array}{c}\text { 1. Proportion of adverse events and } \\
\text { laboratory abnormalities }\end{array}$ \\
$\begin{array}{l}\text { Semaglutide, } \\
\text { firsocostat, cilofexor }\end{array}$ & 2 & NCT03987074 & $2019.7-2020.7$ & NASH fibrosis (F2-3) & 109 & $\begin{array}{c}\text { Safety and tolerability of combination } \\
\text { without worsening of NASH } \\
\text { therapy }\end{array}$ \\
$\begin{array}{l}\text { Tropifexor, } \\
\text { licogliflozin }\end{array}$ & 2 & $\begin{array}{c}\text { ELIVATE, } \\
\text { NCT04065841 }\end{array}$ & $2019.11-2022.4$ & NASH fibrosis (F2-3) & 210 & $\begin{array}{c}\text { NASH resolution without worsening of } \\
\text { fibrosis }\end{array}$ \\
\hline
\end{tabular}

$\mathrm{NASH}$, nonalcoholic steatohepatitis. 


\section{Semaglutide, firsocostat, and cilofexor}

In a phase 2 study of the combination of semaglutide, firsocostat, and cilofexor, 109 patients with NASH fibrosis (stages 2/3) were randomly assigned to the semaglutide group, semaglutide+firsocostat group, semaglutide+cilofexor $30 \mathrm{mg}$ group, semaglutide+cilofexor $100 \mathrm{mg}$ group, or semaglutide+firsocos tat+cilofexor group (NCT03987074) (Table 3). The primary objective was to evaluate the safety and tolerability of the study $\operatorname{drug}(\mathrm{s})$ in adult patients with NASH.

\section{TXR and licogliflozin}

Licogliflozin is a once-daily, oral, SGLT1/2 dual inhibitor. A phase 2, randomized, double-blind, parallel-group, multicenter study is assessing the efficacy, safety, and tolerability of oral TXR and licogliflozin combination therapy, compared to the monotherapies, in patients with NASH and liver fibrosis. The primary endpoint is the proportion of patients with resolution of NASH and no worsening of fibrosis or improvement in fibrosis by at least one stage without worsening of NASH at week 48 compared with baseline (ELIVATE, NCT04065841) (Table 3).

\section{CONCLUSION}

Although vitamin E, pioglitazone, and liraglutide improve liver histology, there is a no FDA approved drug for NASH. Therefore, weight loss by lifestyle modification, including diet and exercise, is the mainstay of NAFLD treatment. This review summarizes the pivotal phase 2 and 3 studies based on the mechanisms of action in NASH treatment (Fig. 2). Five phar-

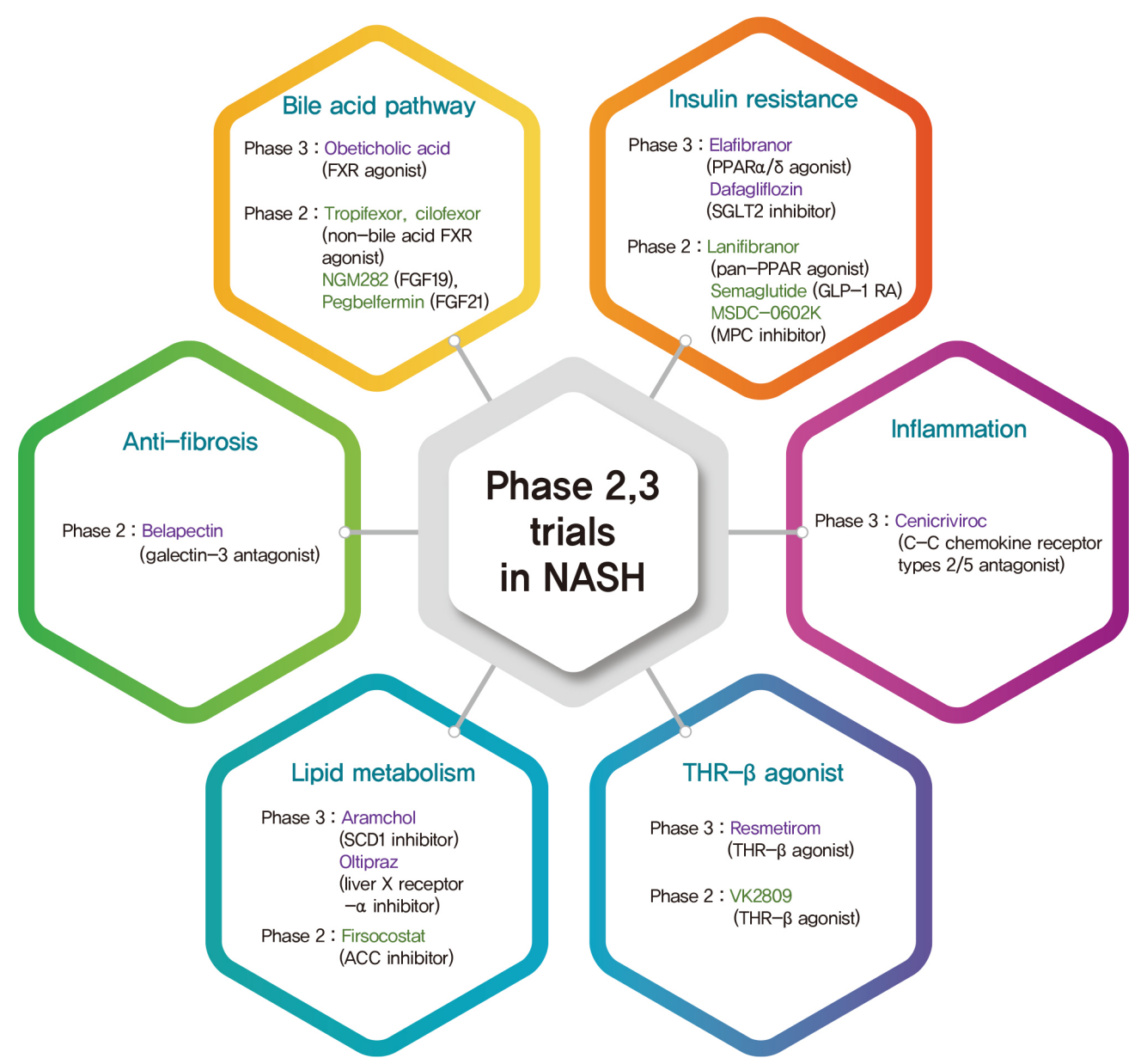

Fig. 2. The classification of phase 2,3 trials based on mechanism of action in nonalcoholic steatohepatitis (NASH) treatment. FXR, farnesoid X receptor; FGF, fibroblast growth factor; PPAR, peroxisome proliferator-activated receptor; SGLT2, sodium glucose cotransporter 2; GLP-1 RA, glucagon-like peptide-1 receptor agonist; MPC, mitochondrial pyruvate carrier; SCD1, stearoylCoA desaturase 1; ACC, acetyl-coenzyme A carboxylase; THR- $\beta$, thyroid hormone receptor- $\beta$. 
macologic agents-OCA, elafibranor, CVC, resmetirom, and aramchol-are under evaluation in large, histology-based phase 3 trials. Based on the results of these trials, new and effective drugs for NASH are expected within 2 to 4 years. Several phase 2 trials are ongoing for various agents, including nonbile acid FXR agonists, FGF19 and 21 analogues, GLP-1 RA, SGLT2 inhibitors, pan-PPAR agonists, MPC inhibitors, ACC inhibitors, and Gal-3 antagonists. Combination treatments are also being evaluated. Because NASH is a multifactorial disease, drug combinations show therapeutic potential. Finally, future treatment strategies will comprise combination treatments and precision medicine based on the different phenotypes of $\mathrm{NASH}$ and treatment response of the individual patient.

\section{CONFLICTS OF INTEREST}

No potential conflict of interest relevant to this article was reported.

\section{ORCID}

Soung Won Jeong https://orcid.org/0000-0003-2855-6011

\section{ACKNOWLEDGMENTS}

This work was supported by the Soonchunhyang University Research Fund and the National Research Foundation of Korea grant funded by the Korea government (2020R1F1A1076282).

\section{REFERENCES}

1. Younossi ZM, Koenig AB, Abdelatif D, Fazel Y, Henry L, Wymer M. Global epidemiology of nonalcoholic fatty liver disease: meta-analytic assessment of prevalence, incidence, and outcomes. Hepatology 2016;64:73-84.

2. Angulo P, Kleiner DE, Dam-Larsen S, Adams LA, Bjornsson ES, Charatcharoenwitthaya P, Mills PR, Keach JC, Lafferty HD, Stahler A, Haflidadottir S, Bendtsen F. Liver fibrosis, but no other histologic features, is associated with long-term outcomes of patients with nonalcoholic fatty liver disease. Gastroenterology 2015;149:389-97.

3. Musso G, Gambino R, Cassader M, Pagano G. Meta-analysis: natural history of non-alcoholic fatty liver disease (NAFLD) and diagnostic accuracy of non-invasive tests for liver disease severity. Ann Med 2011;43:617-49.
4. Vernon G, Baranova A, Younossi ZM. Systematic review: the epidemiology and natural history of non-alcoholic fatty liver disease and non-alcoholic steatohepatitis in adults. Aliment Pharmacol Ther 2011;34:274-85.

5. Rafiq N, Bai C, Fang Y, Srishord M, McCullough A, Gramlich T, Younossi ZM. Long-term follow-up of patients with nonalcoholic fatty liver. Clin Gastroenterol Hepatol 2009;7:234-8.

6. Sayiner M, Koenig A, Henry L, Younossi ZM. Epidemiology of nonalcoholic fatty liver disease and nonalcoholic steatohepatitis in the united states and the rest of the world. Clin Liver Dis 2016;20:205-14.

7. GBD 2015 Mortality and Causes of Death Collaborators. Global, regional, and national life expectancy, all-cause mortality, and cause-specific mortality for 249 causes of death, 1980-2015: a systematic analysis for the Global Burden of Disease Study 2015. Lancet 2016;388:1459-544.

8. Younossi ZM, Stepanova M, Rafiq N, Makhlouf H, Younoszai Z, Agrawal R, Goodman Z. Pathologic criteria for nonalcoholic steatohepatitis: interprotocol agreement and ability to predict liver-related mortality. Hepatology 2011;53:1874-82.

9. Hossain N, Stepanova M, Afendy A, Nader F, Younossi Y, Rafiq N, Goodman Z, Younossi ZM. Non-alcoholic steatohepatitis (NASH) in patients with polycystic ovarian syndrome (PCOS). Scand J Gastroenterol 2011;46:479-84.

10. Konerman MA, Jones JC, Harrison SA. Pharmacotherapy for NASH: current and emerging. J Hepatol 2018;68:362-75.

11. Yoo JJ, Kim W, Kim MY, Jun DW, Kim SG, Yeon JE, Lee JW, Cho YK, Park SH, Sohn JH; the Korean Association for the Study of the Liver (KASL)-Korea Nonalcoholic fatty liver Study Group (KNSG). Recent research trends and updates on nonalcoholic fatty liver disease. Clin Mol Hepatol 2019;25:111.

12. Cusi K, Orsak B, Bril F, Lomonaco R, Hecht J, Ortiz-Lopez C, Tio F, Hardies J, Darland C, Musi N, Webb A, Portillo-Sanchez P. Long-term pioglitazone treatment for patients with nonalcoholic steatohepatitis and prediabetes or type 2 diabetes mellitus: a randomized trial. Ann Intern Med 2016;165:30515.

13. Aithal GP, Thomas JA, Kaye PV, Lawson A, Ryder SD, Spendlove I, Austin AS, Freeman JG, Morgan L, Webber J. Randomized, placebo-controlled trial of pioglitazone in nondiabetic subjects with nonalcoholic steatohepatitis. Gastroenterology 2008;135:1176-84.

14. Sanyal AJ, Chalasani N, Kowdley KV, McCullough A, Diehl AM, Bass NM, Neuschwander-Tetri BA, Lavine JE, Tonascia J, 
Unalp A, Van Natta M, Clark J, Brunt EM, Kleiner DE, Hoofnagle JH, Robuck PR; NASH CRN. Pioglitazone, vitamin E, or placebo for nonalcoholic steatohepatitis. N Engl J Med 2010; 362:1675-85.

15. Armstrong MJ, Gaunt P, Aithal GP, Barton D, Hull D, Parker R, Hazlehurst JM, Guo K; LEAN trial team, Abouda G, Aldersley MA, Stocken D, Gough SC, Tomlinson JW, Brown RM, Hubscher SG, Newsome PN. Liraglutide safety and efficacy in patients with non-alcoholic steatohepatitis (LEAN): a multicentre, double-blind, randomised, placebo-controlled phase 2 study. Lancet 2016;387:679-90.

16. Caldwell S. NASH therapy: omega 3 supplementation, vitamin E, insulin sensitizers and statin drugs. Clin Mol Hepatol 2017;23:103-8.

17. Bjelakovic G, Nikolova D, Gluud LL, Simonetti RG, Gluud C. Mortality in randomized trials of antioxidant supplements for primary and secondary prevention: systematic review and meta-analysis. JAMA 2007;297:842-57.

18. Abner EL, Schmitt FA, Mendiondo MS, Marcum JL, Kryscio RJ. Vitamin E and all-cause mortality: a meta-analysis. Curr Aging Sci 2011;4:158-70.

19. Schurks M, Glynn RJ, Rist PM, Tzourio C, Kurth T. Effects of vitamin $\mathrm{E}$ on stroke subtypes: meta-analysis of randomised controlled trials. BMJ 2010;341:c5702.

20. Klein EA, Thompson IM Jr, Tangen CM, Crowley JJ, Lucia MS, Goodman PJ, Minasian LM, Ford LG, Parnes HL, Gaziano JM, Karp DD, Lieber MM, Walther PJ, Klotz L, Parsons JK, Chin JL, Darke AK, Lippman SM, Goodman GE, Meyskens FL Jr, Baker LH. Vitamin E and the risk of prostate cancer: the Selenium and Vitamin E Cancer Prevention Trial (SELECT). JAMA 2011;306:1549-56.

21. Vilar-Gomez E, Martinez-Perez Y, Calzadilla-Bertot L, TorresGonzalez A, Gra-Oramas B, Gonzalez-Fabian L, Friedman SL, Diago M, Romero-Gomez M. Weight loss through lifestyle modification significantly reduces features of nonalcoholic steatohepatitis. Gastroenterology 2015;149:367-78.

22. St George A, Bauman A, Johnston A, Farrell G, Chey T, George J. Independent effects of physical activity in patients with nonalcoholic fatty liver disease. Hepatology 2009;50:6876.

23. Sung KC, Ryu S, Lee JY, Kim JY, Wild SH, Byrne CD. Effect of exercise on the development of new fatty liver and the resolution of existing fatty liver. J Hepatol 2016;65:791-7.

24. Chalasani N, Younossi Z, Lavine JE, Charlton M, Cusi K, Rinella M, Harrison SA, Brunt EM, Sanyal AJ. The diagnosis and management of nonalcoholic fatty liver disease: practice guidance from the American Association for the Study of Liver Diseases. Hepatology 2018;67:328-57.

25. Neuschwander-Tetri BA, Loomba R, Sanyal AJ, Lavine JE, Van Natta ML, Abdelmalek MF, Chalasani N, Dasarathy S, Diehl AM, Hameed B, Kowdley KV, McCullough A, Terrault N, Clark JM, Tonascia J, Brunt EM, Kleiner DE, Doo E; NASH Clinical Research Network. Farnesoid X nuclear receptor ligand obeticholic acid for non-cirrhotic, non-alcoholic steatohepatitis (FLINT): a multicentre, randomised, placebo-controlled trial. Lancet 2015;385:956-65.

26. Ratziu V, Harrison SA, Francque S, Bedossa P, Lehert P, Serfaty L, Romero-Gomez M, Boursier J, Abdelmalek M, Caldwell S, Drenth J, Anstee QM, Hum D, Hanf R, Roudot A, Megnien S, Staels B, Sanyal A; GOLDEN-505 Investigator Study Group. Elafibranor, an agonist of the peroxisome proliferator-activated receptor- $\alpha$ and $-\delta$, induces resolution of nonalcoholic steatohepatitis without fibrosis worsening. Gastroenterology 2016;150:1147-59.

27. Friedman SL, Ratziu V, Harrison SA, Abdelmalek MF, Aithal GP, Caballeria J, Francque S, Farrell G, Kowdley KV, Craxi A, Simon K, Fischer L, Melchor-Khan L, Vest J, Wiens BL, Vig P, Seyedkazemi S, Goodman Z, Wong VW, Loomba R, Tacke F, Sanyal A, Lefebvre E. A randomized, placebo-controlled trial of cenicriviroc for treatment of nonalcoholic steatohepatitis with fibrosis. Hepatology 2018;67:1754-67.

28. Harrison SA, Bashir MR, Guy CD, Zhou R, Moylan CA, Frias JP, Alkhouri N, Bansal MB, Baum S, Neuschwander-Tetri BA, Taub R, Moussa SE. Resmetirom (MGL-3196) for the treatment of non-alcoholic steatohepatitis: a multicentre, randomised, double-blind, placebo-controlled, phase 2 trial. Lancet 2019;394:2012-24.

29. Ratziu V, Ladron-De-Guevara L, Safadi R, Poordad F, Fuster F, Harrison SA, Arrese M, Fargion S, Ben-Bashat D, Lackner C, Gorfine T, Oren R, Loomba R, Sanyal AJ; the ARREST investigator study group. One-year results of the global phase $2 \mathrm{~b}$ randomized placebo-controlled ARREST trial of aramchol, a stearoyl CoA desaturase inhibitor, in patients with NASH. Hepatology 2018;68:1447A-8A.

30. Pellicciari R, Costantino G, Camaioni E, Sadeghpour BM, Entrena A, Willson TM, Fiorucci S, Clerici C, Gioiello A. Bile acid derivatives as ligands of the farnesoid $\mathrm{X}$ receptor: synthesis, evaluation, and structure-activity relationship of a series of body and side chain modified analogues of chenodeoxycholic acid. J Med Chem 2004;47:4559-69. 
31. Jhaveri MA, Kowdley KV. New developments in the treatment of primary biliary cholangitis: role of obeticholic acid. Ther Clin Risk Manag 2017;13:1053-60.

32. Adorini L, Pruzanski M, Shapiro D. Farnesoid X receptor targeting to treat nonalcoholic steatohepatitis. Drug Discov Today 2012;17:988-97.

33. Pellicciari R, Fiorucci S, Camaioni E, Clerici C, Costantino G, Maloney PR, Morelli A, Parks DJ, Willson TM. 6Alpha-ethylchenodeoxycholic acid (6-ECDCA), a potent and selective FXR agonist endowed with anticholestatic activity. J Med Chem 2002;45:3569-72.

34. Mudaliar S, Henry RR, Sanyal AJ, Morrow L, Marschall HU, Kipnes M, Adorini L, Sciacca CI, Clopton P, Castelloe E, Dillon P, Pruzanski M, Shapiro D. Efficacy and safety of the farnesoid X receptor agonist obeticholic acid in patients with type 2 diabetes and nonalcoholic fatty liver disease. Gastroenterology 2013;145:574-82.

35. Younossi ZM, Ratziu V, Loomba R, Rinella M, Anstee QM, Goodman Z, Bedossa P, Geier A, Beckebaum S, Newsome PN, Sheridan D, Sheikh MY, Trotter J, Knapple W, Lawitz E, Abdelmalek MF, Kowdley KV, Montano-Loza AJ, Boursier J, Mathurin P, Bugianesi E, Mazzella G, Olveira A, Cortez-Pinto H, Graupera I, Orr D, Gluud LL, Dufour JF, Shapiro D, Campagna J, Zaru L, MacConell L, Shringarpure R, Harrison S, Sanyal AJ; REGENERATE Study Investigators. Obeticholic acid for the treatment of non-alcoholic steatohepatitis: interim analysis from a multicentre, randomised, placebo-controlled phase 3 trial. Lancet 2019;394:2184-96.

36. Pockros PJ, Fuchs M, Freilich B, Schiff E, Kohli A, Lawitz EJ, Hellstern PA, Owens-Grillo J, Van Biene C, Shringarpure R, MacConell L, Shapiro D, Cohen DE. CONTROL: a randomized phase 2 study of obeticholic acid and atorvastatin on lipoproteins in nonalcoholic steatohepatitis patients. Liver Int 2019;39:2082-93.

37. Eaton JE, Vuppalanchi R, Reddy R, Sathapathy S, Ali B, Kamath PS. Liver injury in patients with cholestatic liver disease treated with obeticholic acid. Hepatology 2020;71:1511-4.

38. Tully DC, Rucker PV, Chianelli D, Williams J, Vidal A, Alper PB, Mutnick D, Bursulaya B, Schmeits J, Wu X, Bao D, Zoll J, Kim Y, Groessl T, McNamara P, Seidel HM, Molteni V, Liu B, Phimister A, Joseph SB, Laffitte B. Discovery of tropifexor (LJN452), a highly potent non-bile acid fxr agonist for the treatment of cholestatic liver diseases and nonalcoholic steatohepatitis (NASH). J Med Chem 2017;60:9960-73.

39. Sanyal AJ, Lopez PM, Lawitz E, Kim W, Huang JF, Andreone P,
Goh BBG, Chen YC, Ratziu V, Kim YJ, Ryan M, Weltman M, Geier A, Loeffler J, Schaefer FA, Vaidyanathan S, Brass CA. Tropifexor (TXR), an FXR agonist for the treatment of NASH: interim results from first two parts of phase $2 \mathrm{~b}$ study flightFXR. Hepatology 2018;68:1460A-1A.

40. Sanyal A, Lopez P, Lawitz E, Kim W, Huang JF, Andreone P, Goh GBB, Chen YC, Ratziu V, Kim YJ, Ryan M, Weltman M, Geier A, Loeffler J, Schaefer F, Vaidyanathan S, Martic M, Brass C. SAT-357. Tropifexor, a farnesoid X receptor agonist for the treatment of non-alcoholic steatohepatitis: Interim results based on baseline body mass index from first two parts of Phase 2b study FLIGHT-FXR. J Hepatol 2019;70(1 Suppl): E796-7.

41. Trauner M, Gulamhusein A, Hameed B, Caldwell S, Shiffman ML, Landis C, Eksteen B, Agarwal K, Muir A, Rushbrook S, Lu X, Xu J, Chuang JC, Billin AN, Li G, Chung C, Subramanian GM, Myers RP, Bowlus CL, Kowdley KV. The nonsteroidal farnesoid X receptor agonist cilofexor (GS-9674) improves markers of cholestasis and liver injury in patients with primary sclerosing cholangitis. Hepatology 2019;70:788-801.

42. Kirby B, Djedjos CS, Birkebak J, Song Q, Grycz K, Weston J, Subramanian M, Watkins W, Myers RP, Mathias A. Evaluation of the safety and pharmacokinetic effects of the oral, non-steroidal farnesoid X receptor agonist GS-9674 in healthy volunteers. Hepatology 2016;63:574A-5A.

43. Lawitz E, Herring R Jr, Younes ZH, Gane E, Ruane P, Schall RA, Jia C, Xu R, Mccolgan B, Djedjos S, Subramanian M, Mchutchison JG, Myers R, Middleton M, Li K, Hellerstein M, Kwo P, Noureddin M, Harrison S. Proof of concept study of an apoptosis-signal regulating kinase (ASK1) inhibitor (selonsertib) in combination with an acetyl-CoA carboxylase inhibitor (GS-0976) or a farnesoid X receptor agonist (GS-9674) in NASH. J Hepatol 2018;68 Suppl 1:S57.

44. Patel K, Harrison SA, Elkhashab M, Trotter JF, Herring R, Rojter SE, Kayali Z, Wong VW, Greenbloom S, Jayakumar S, Shiffman ML, Freilich B, Lawitz EJ, Gane EJ, Harting E, Xu J, Billin AN, Chung C, Djedjos CS, Subramanian GM, Myers RP, Middleton MS, Rinella M, Noureddin M. Cilofexor, a nonsteroidal FXR agonist, in patients with noncirrhotic NASH: a phase 2 randomized controlled trial. Hepatology 2020;72:58-71.

45. Chianelli D, Rucker PV, Roland J, Tully DC, Nelson J, Liu X, Bursulaya B, Hernandez ED, Wu J, Prashad M, Schlama T, Liu Y, Chu A, Schmeits J, Huang DJ, Hill R, Bao D, Zoll J, Kim Y, Groessl T, McNamara P, Liu B, Richmond W, Sancho-Marti- 
nez I, Phimister A, Seidel HM, Badman MK, Joseph SB, Laffitte B, Molteni V. Nidufexor (LMB763), a novel FXR modulator for the treatment of nonalcoholic steatohepatitis. J Med Chem 2020;63:3868-80.

46. Erstad DJ, Farrar CT, Ghoshal S, Masia R, Ferreira DS, Chen YI, Choi JK, Wei L, Waghorn PA, Rotile NJ, Tu C, GrahamO’Regan KA, Sojoodi M, Li S, Li Y, Wang G, Corey KE, Or YS, Jiang L, Tanabe KK, Caravan P, Fuchs BC. Molecular magnetic resonance imaging accurately measures the antifibrotic effect of EDP-305, a novel farnesoid X receptor agonist. Hepatol Commun 2018;2:821-35.

47. Ornitz DM, Itoh N. The fibroblast growth factor signaling pathway. Wiley Interdiscip Rev Dev Biol 2015;4:215-66.

48. Schaap FG, Trauner M, Jansen PL. Bile acid receptors as targets for drug development. Nat Rev Gastroenterol Hepatol 2014;11:55-67.

49. Harrison SA, Rinella ME, Abdelmalek MF, Trotter JF, Paredes AH, Arnold HL, Kugelmas M, Bashir MR, Jaros MJ, Ling L, Rossi SJ, DePaoli AM, Loomba R. NGM282 for treatment of non-alcoholic steatohepatitis: a multicentre, randomised, double-blind, placebo-controlled, phase 2 trial. Lancet 2018; 391:1174-85.

50. Harrison SA, Rossi SJ, Paredes AH, Trotter JF, Bashir MR, Guy CD, Banerjee R, Jaros MJ, Owers S, Baxter BA, Ling L, DePaoli AM. NGM282 improves liver fibrosis and histology in 12 weeks in patients with nonalcoholic steatohepatitis. Hepatology 2020;71:1198-212.

51. Cyphert HA, Ge X, Kohan AB, Salati LM, Zhang Y, Hillgartner FB. Activation of the farnesoid $X$ receptor induces hepatic expression and secretion of fibroblast growth factor 21. J Biol Chem 2012;287:25123-38.

52. Kharitonenkov A, Larsen P. FGF21 reloaded: challenges of a rapidly growing field. Trends Endocrinol Metab 2011;22:81-6.

53. Sonoda J, Chen MZ, Baruch A. FGF21-receptor agonists: an emerging therapeutic class for obesity-related diseases. Horm Mol Biol Clin Investig 2017;30:20170002.

54. Sanyal A, Charles ED, Neuschwander-Tetri BA, Loomba R, Harrison SA, Abdelmalek MF, Lawitz EJ, Halegoua-DeMarzio D, Kundu S, Noviello S, Luo Y, Christian R. Pegbelfermin (BMS-986036), a PEGylated fibroblast growth factor 21 analogue, in patients with non-alcoholic steatohepatitis: a randomised, double-blind, placebo-controlled, phase 2a trial. Lancet 2019;392:2705-17.

55. Berger J, Moller DE. The mechanisms of action of PPARs. Annu Rev Med 2002;53:409-35.
56. Pawlak M, Lefebvre P, Staels B. Molecular mechanism of PPARa action and its impact on lipid metabolism, inflammation and fibrosis in non-alcoholic fatty liver disease. J Hepatol 2015;62:720-33.

57. Francque S, Verrijken A, Caron S, Prawitt J, Paumelle R, Derudas B, Lefebvre P, Taskinen MR, Van Hul W, Mertens I, Hubens G, Van Marck E, Michielsen P, Van Gaal L, Staels B. PPARa gene expression correlates with severity and histological treatment response in patients with non-alcoholic steatohepatitis. J Hepatol 2015;63:164-73.

58. Bojic LA, Huff MW. Peroxisome proliferator-activated receptor $\delta$ : a multifaceted metabolic player. Curr Opin Lipidol 2013; 24:171-7.

59. Riserus U, Sprecher D, Johnson T, Olson E, Hirschberg S, Liu A, Fang Z, Hegde P, Richards D, Sarov-Blat L, Strum JC, Basu S, Cheeseman J, Fielding BA, Humphreys SM, Danoff T, Moore NR, Murgatroyd P, O'Rahilly S, Sutton P, Willson T, Hassall D, Frayn KN, Karpe F. Activation of peroxisome proliferator-activated receptor (PPAR)delta promotes reversal of multiple metabolic abnormalities, reduces oxidative stress, and increases fatty acid oxidation in moderately obese men. Diabetes 2008;57:332-9.

60. Boubia B, Poupardin O, Barth M, Binet J, Peralba P, Mounier L, Jacquier E, Gauthier E, Lepais V, Chatar M, Ferry S, Thourigny A, Guillier F, Llacer J, Amaudrut J, Dodey P, Lacombe O, Masson P, Montalbetti C, Wettstein G, Luccarini JM, Legendre C, Junien JL, Broqua P. Design, synthesis, and evaluation of a novel series of indole sulfonamide peroxisome proliferator activated receptor (PPAR) $\alpha / \gamma / \delta$ triple activators: discovery of lanifibranor, a new antifibrotic clinical candidate. J Med Chem 2018;61:2246-65.

61. American Diabetes Association. 8. Pharmacologic approaches to glycemic treatment: standards of medical care in diabetes-2018. Diabetes Care 2018;41:S73-85.

62. Eng C, Kramer CK, Zinman B, Retnakaran R. Glucagon-like peptide-1 receptor agonist and basal insulin combination treatment for the management of type 2 diabetes: a systematic review and meta-analysis. Lancet 2014;384:2228-34.

63. Eguchi Y, Kitajima Y, Hyogo H, Takahashi H, Kojima M, Ono M, Araki N, Tanaka K, Yamaguchi M, Matsuda Y, Ide Y, Otsuka T, Ozaki I, Ono N, Eguchi T, Anzai K; Japan Study Group for NAFLD (JSG-NAFLD). Pilot study of liraglutide effects in non-alcoholic steatohepatitis and non-alcoholic fatty liver disease with glucose intolerance in Japanese patients (LEAN-J). Hepatol Res 2015;45:269-78. 
64. Armstrong MJ, Houlihan DD, Rowe IA, Clausen WH, Elbrønd B, Gough SC, Tomlinson JW, Newsome PN. Safety and efficacy of liraglutide in patients with type 2 diabetes and elevated liver enzymes: individual patient data meta-analysis of the LEAD program. Aliment Pharmacol Ther 2013;37:234-42.

65. Kenny PR, Brady DE, Torres DM, Ragozzino L, Chalasani N, Harrison SA. Exenatide in the treatment of diabetic patients with non-alcoholic steatohepatitis: a case series. Am J Gastroenterol 2010;105:2707-9.

66. Buse JB, Klonoff DC, Nielsen LL, Guan X, Bowlus CL, Holcombe JH, Maggs DG, Wintle ME. Metabolic effects of two years of exenatide treatment on diabetes, obesity, and hepatic biomarkers in patients with type 2 diabetes: an interim analysis of data from the open-label, uncontrolled extension of three double-blind, placebo-controlled trials. Clin Ther 2007; 29:139-53.

67. Shimizu M, Suzuki K, Kato K, Jojima T, Iijima T, Murohisa T, Iijima M, Takekawa H, Usui I, Hiraishi H, Aso Y. Evaluation of the effects of dapagliflozin, a sodium-glucose co-transporter-2 inhibitor, on hepatic steatosis and fibrosis using transient elastography in patients with type 2 diabetes and non-alcoholic fatty liver disease. Diabetes Obes Metab 2019;21:285-92.

68. Kurinami N, Sugiyama S, Yoshida A, Hieshima K, Miyamoto F, Kajiwara K, Jinnouch K, Jinnouchi T, Jinnouchi H. Dapagliflozin significantly reduced liver fat accumulation associated with a decrease in abdominal subcutaneous fat in patients with inadequately controlled type 2 diabetes mellitus. Diabetes Res Clin Pract 2018;142:254-63.

69. Soccio RE, Chen ER, Lazar MA. Thiazolidinediones and the promise of insulin sensitization in type 2 diabetes. Cell Metab 2014;20:573-91.

70. Chen Z, Vigueira PA, Chambers KT, Hall AM, Mitra MS, Qi N, McDonald WG, Colca JR, Kletzien RF, Finck BN. Insulin resistance and metabolic derangements in obese mice are ameliorated by a novel peroxisome proliferator-activated receptor $\gamma$-sparing thiazolidinedione. J Biol Chem 2012;287: 23537-48.

71. McCommis KS, Hodges WT, Brunt EM, Nalbantoglu I, McDonald WG, Holley C, Fujiwara H, Schaffer JE, Colca JR, Finck BN. Targeting the mitochondrial pyruvate carrier attenuates fibrosis in a mouse model of nonalcoholic steatohepatitis. Hepatology 2017;65:1543-56.

72. Colca JR, McDonald WG, Cavey GS, Cole SL, Holewa DD, Brightwell-Conrad AS, Wolfe CL, Wheeler JS, Coulter KR, Kilkuskie PM, Gracheva E, Korshunova Y, Trusgnich M, Karr
R, Wiley SE, Divakaruni AS, Murphy AN, Vigueira PA, Finck $\mathrm{BN}$, Kletzien RF. Identification of a mitochondrial target of thiazolidinedione insulin sensitizers (mTOT): relationship to newly identified mitochondrial pyruvate carrier proteins. PLoS One 2013;8:e61551.

73. Colca JR, McDonald WG, Adams WJ. MSDC-0602K, a metabolic modulator directed at the core pathology of non-alcoholic steatohepatitis. Expert Opin Investig Drugs 2018;27:631-6.

74. Harrison SA, Alkhouri N, Davison BA, Sanyal A, Edwards C, Colca JR, Lee BH, Loomba R, Cusi K, Kolterman O, Cotter G, Dittrich HC. Insulin sensitizer MSDC-0602K in non-alcoholic steatohepatitis: a randomized, double-blind, placebo-controlled phase IIb study. J Hepatol 2020;72:613-26.

75. Mossanen JC, Krenkel O, Ergen C, Govaere O, Liepelt A, Puengel T, Heymann F, Kalthoff S, Lefebvre E, Eulberg D, Luedde T, Marx G, Strassburg CP, Roskams T, Trautwein C, Tacke F. Chemokine (C-C motif) receptor 2-positive monocytes aggravate the early phase of acetaminophen-induced acute liver injury. Hepatology 2016;64:1667-82.

76. Lefebvre E, Moyle G, Reshef R, Richman LP, Thompson M, Hong F, Chou HL, Hashiguchi T, Plato C, Poulin D, Richards T, Yoneyama H, Jenkins H, Wolfgang G, Friedman SL. Antifibrotic effects of the dual CCR2/CCR5 antagonist cenicriviroc in animal models of liver and kidney fibrosis. PLoS One 2016; 11:e0158156.

77. Schwabe RF, Bataller R, Brenner DA. Human hepatic stellate cells express CCR5 and RANTES to induce proliferation and migration. Am J Physiol Gastrointest Liver Physiol 2003;285: G949-58.

78. Friedman S, Sanyal A, Goodman Z, Lefebvre E, Gottwald M, Fischer L, Ratziu V. Efficacy and safety study of cenicriviroc for the treatment of non-alcoholic steatohepatitis in adult subjects with liver fibrosis: CENTAUR Phase 2b study design. Contemp Clin Trials 2016;47:356-65.

79. Sinha RA, Bruinstroop E, Singh BK, Yen PM. Nonalcoholic fatty liver disease and hypercholesterolemia: roles of thyroid hormones, metabolites, and agonists. Thyroid 2019;29:1173-91.

80. Bohinc BN, Michelotti G, Xie G, Pang H, Suzuki A, Guy CD, Piercy D, Kruger L, Swiderska-Syn M, Machado M, Pereira T, Zavacki AM, Abdelmalek M, Diehl AM. Repair-related activation of hedgehog signaling in stromal cells promotes intrahepatic hypothyroidism. Endocrinology 2014;155:4591-601.

81. Loomba R, Neutel J, Mohseni R, Bernard D, Severance R, Dao M, Saini S, Margaritescu C, Homer K, Tran B, Mancini M, Masamune H, Lian B. VK2809. A novel liver-directed thyroid 
receptor beta agonist, significantly reduces liver fat with both low and high doses in patients with non-alcoholic fatty liver disease: a phase 2 randomized, placebo-controlled trial. J Hepatol 2019;70(1 Suppl):E150-1.

82. Leikin-Frenkel A, Gonen A, Shaish A, Goldiner I, LeikinGobbi D, Konikoff FM, Harats D, Gilat T. Fatty acid bile acid conjugate inhibits hepatic stearoyl coenzyme A desaturase and is non-atherogenic. Arch Med Res 2010;41:397-404.

83. Abu-Elheiga L, Brinkley WR, Zhong L, Chirala SS, Woldegiorgis G, Wakil SJ. The subcellular localization of acetyl-CoA carboxylase 2. Proc Natl Acad Sci U S A 2000;97:1444-9.

84. Brooks SC 3rd, Brooks JS, Lee WH, Lee MG, Kim SG. Therapeutic potential of dithiolethiones for hepatic diseases. Pharmacol Ther 2009;124:31-43.

85. Winder WW, Hardie DG. AMP-activated protein kinase, a metabolic master switch: possible roles in type 2 diabetes. Am J Physiol 1999;277:E1-10.

86. Kim W, Kim BG, Lee JS, Lee CK, Yeon JE, Chang MS, Kim JH, Kim H, Yi S, Lee J, Cho JY, Kim SG, Lee JH, Kim YJ. Randomised clinical trial: the efficacy and safety of oltipraz, a liver $\mathrm{X}$ receptor alpha-inhibitory dithiolethione in patients with non-alcoholic fatty liver disease. Aliment Pharmacol Ther 2017;45:1073-83.

87. Abu-Elheiga L, Jayakumar A, Baldini A, Chirala SS, Wakil SJ. Human acetyl-CoA carboxylase: characterization, molecular cloning, and evidence for two isoforms. Proc Natl Acad Sci U S A 1995;92:4011-5.

88. Harriman G, Greenwood J, Bhat S, Huang X, Wang R, Paul D, Tong L, Saha AK, Westlin WF, Kapeller R, Harwood HJ Jr. Acetyl-CoA carboxylase inhibition by ND-630 reduces hepatic steatosis, improves insulin sensitivity, and modulates dyslipidemia in rats. Proc Natl Acad Sci U S A 2016;113:E1796-805.

89. Harwood HJ Jr. Acetyl-CoA carboxylase inhibition for the treatment of metabolic syndrome. Curr Opin Investig Drugs 2004;5:283-9.

90. Harwood HJ Jr. Treating the metabolic syndrome: acetyl-CoA carboxylase inhibition. Expert Opin Ther Targets 2005;9:267-81.

91. Loomba R, Kayali Z, Noureddin M, Ruane P, Lawitz EJ, Bennett M, Wang L, Harting E, Tarrant JM, McColgan BJ, Chung C, Ray AS, Subramanian GM, Myers RP, Middleton MS, Lai M, Charlton M, Harrison SA. GS-0976 reduces hepatic steatosis and fibrosis markers in patients with nonalcoholic fatty liver disease. Gastroenterology 2018;155:1463-73.

92. Barondes SH, Castronovo V, Cooper DN, Cummings RD,
Drickamer K, Feizi T, Gitt MA, Hirabayashi J, Hughes C, Kasai K, Leffler H, Liu FT, Lotan R, Mercurio AM, Monsigny M, Pillai S, Poirer F, Raz A, Rigby PWJ, Rini JM, Wang JL. Galectins: a family of animal beta-galactoside-binding lectins. Cell 1994;76:597-8.

93. Ochieng J, Fridman R, Nangia-Makker P, Kleiner DE, Liotta LA, Stetler-Stevenson WG, Raz A. Galectin-3 is a novel substrate for human matrix metalloproteinases-2 and -9. Biochemistry 1994;33:14109-14.

94. Yang RY, Hsu DK, Liu FT. Expression of galectin-3 modulates T-cell growth and apoptosis. Proc Natl Acad Sci U S A 1996; 93:6737-42.

95. Jeng KC, Frigeri LG, Liu FT. An endogenous lectin, galectin-3 (epsilon BP/Mac-2), potentiates IL-1 production by human monocytes. Immunol Lett 1994;42:113-6.

96. Sano H, Hsu DK, Yu L, Apgar JR, Kuwabara I, Yamanaka T, Hirashima M, Liu FT. Human galectin-3 is a novel chemoattractant for monocytes and macrophages. J Immunol 2000; 165:2156-64.

97. Tellez-Sanz R, Garcia-Fuentes L, Vargas-Berenguel A. Human galectin-3 selective and high affinity inhibitors. Present state and future perspectives. Curr Med Chem 2013;20:2979-90.

98. Harrison SA, Marri SR, Chalasani N, Kohli R, Aronstein W, Thompson GA, Irish W, Miles MV, Xanthakos SA, Lawitz E, Noureddin M, Schiano TD, Siddiqui M, Sanyal A, Neuschwander-Tetri BA, Traber PG. Randomised clinical study: GR-MD-02, a galectin-3 inhibitor, vs. placebo in patients having non-alcoholic steatohepatitis with advanced fibrosis. Aliment Pharmacol Ther 2016;44:1183-98.

99. Chalasani N, Abdelmalek MF, Garcia-Tsao G, Vuppalanchi R, Alkhouri N, Rinella M, Noureddin M, Pyko M, Shiffman M, Sanyal A, Allgood A, Shlevin H, Horton R, Zomer E, Irish W, Goodman Z, Harrison SA, Traber PG; Belapectin (GRMD-02) Study Investigators. Effects of belapectin, an inhibitor of galectin-3, in patients with nonalcoholic steatohepatitis with cirrhosis and portal hypertension. Gastroenterology 2020; 158:1334-45.

100. Pedrosa M, Seyedkazemi S, Francque S, Sanyal A, Rinella M, Charlton M, Loomba R, Ratziu V, Kochuparampil J, Fischer L, Vaidyanathan S, Anstee QM. A randomized, double-blind, multicenter, phase $2 \mathrm{~b}$ study to evaluate the safety and efficacy of a combination of tropifexor and cenicriviroc in patients with nonalcoholic steatohepatitis and liver fibrosis: study design of the TANDEM trial. Contemp Clin Trials 2020;88: 105889. 